\title{
Trajectories of Delinquency and Parenting Styles
}

\author{
Machteld Hoeve • Arjan Blokland • \\ Judith Semon Dubas • Rolf Loeber • Jan R. M. Gerris • \\ Peter H. van der Laan
}

Published online: 5 September 2007

(C) Springer Science+Business Media, LLC 2007

\begin{abstract}
We investigated trajectories of adolescent delinquent development using data from the Pittsburgh Youth Study and examined the extent to which these different trajectories are differentially predicted by childhood parenting styles. Based on self-reported and official delinquency seriousness, covering ages 10-19, we identified five distinct delinquency trajectories differing in both level and change in seriousness over time: a nondelinquent, minor persisting, moderate desisting, serious persisting, and serious desisting trajectory. More serious delinquents tended to more frequently engage in delinquency, and to report a higher proportion of theft. Proportionally, serious persistent delinquents were the most violent of all trajectory groups. Using cluster analysis we identified three parenting styles: authoritative, authoritarian (moderately supportive), and neglectful (punishing). Controlling for demographic
\end{abstract}

\section{Hoeve · A. Blokland · P. H. van der Laan}

Netherlands Institute for the Study of Crime and Law

Enforcement (NWO-NSCR),

Leiden, The Netherlands

\section{Hoeve $(\bowtie)$}

Department of Educational Sciences, University of Amsterdam, P.O. Box 94208, 1090 GE Amsterdam, The Netherlands

e-mail: m.hoeve@uva.nl

\section{J. S. Dubas}

Department of Developmental Psychology, Utrecht University, Utrecht, The Netherlands

\section{R. Loeber}

Life History Studies, University of Pittsburgh Medical Center, Pittsburgh, PA, USA

\section{J. R. M. Gerris}

Department of Pedagogy: Family and Behavior,

Radboud University Nijmegen,

Nijmegen, The Netherlands characteristics and childhood delinquency, neglectful parenting was more frequent in moderate desisters, serious persisters, and serious desisters, suggesting that parenting styles differentiate non- or minor delinquents from more serious delinquents.

Keywords Delinquency trajectories · Parenting styles · Development $\cdot$ Longitudinal

During childhood the family environment constitutes the basic social ecology in which the child's behavior is manifested, learned, encouraged or suppressed (Dishion and Patterson 2006). Criminologists have long since acknowledged the association between parenting and delinquency (Loeber and Stouthamer-Loeber 1986) and various criminological theories have included parenting behaviors among their explanatory variables (e.g., Hirschi 1969). However, only with the advent of developmental criminology during the 1990s have criminological theories been proposed linking a variety of family factors and parenting practices to specific developmental trajectories of delinquency.

In this study we make use of data from the Pittsburgh Youth Study (PYS), a longitudinal study covering a period of over 14 years. Our aim is to test whether distinct developmental trajectories based on delinquency seriousness can be identified and whether parenting styles are differentially linked to membership of these trajectories.

\section{Parenting and Delinquency}

A delinquent trajectory, the evolution of delinquency over age, can usefully be described by its level (intercept) and its rate of change over time (slope). Developmental crimino- 
logical theories differ in the extent to which they consider between-individual variation on these two dimensions. Some theories account only for differences in the absolute level of delinquency, assuming, often implicitly, the shape of the delinquent trajectory to be relatively similar across individuals (e.g., Gottfredson and Hirschi 1990). Others explicitly recognize variation in both the intercept and slope of delinquent development, linking differently shaped trajectories to different etiological factors, including parenting practices (e.g., Moffitt 1993).

A prominent example of a theory explaining only level differences in delinquent development is Gottfredson and Hirschi's (1990) 'General Theory'. Their theory attributes delinquency to lack of self-control. While recognizing inherent individual differences, Gottfredson and Hirschi claim low levels of self-control to result from parents failing to monitor the child's behavior, to recognize deviant behavior when it occurs, and to punish such behavior (Gottfredson and Hirschi 1990). Other theories go beyond explaining only level differences in delinquency and examine how delinquency changes by age. Moffitt (1993), Patterson (e.g., Patterson and Yoerger 2002), and Lahey and Waldman (2003), for example, offer theories that try to explain why delinquent trajectories are differently shaped for different types of individuals. The basic premise of these models is that children differ, whether continuously (Lahey and Waldman) or discontinuously (Moffitt), in key temperamental and cognitive elements that make up antisocial propensity. According to these typologies difficult children negatively affect their parents' disciplinary strategies, resulting in harsher and inconsistent punishments and parents being less involved in the socialization process. These negative child-parent transactions set a child off on a delinquent path that starts in the early teens, entails many delinquent acts and persists far into adulthood. In contrast, neuropsychologically healthy children with average temperamental profiles, raised in adaptive family environments, are unlikely to develop enduring and serious delinquency trajectories. These children tend to show minor, nonaggressive delinquent trajectories that peak in adolescence reflecting their desire to express autonomy from parental control (Moffitt 1993) or peer pressure to engage in delinquent acts (Lahey and Waldman 2003; Patterson and Yoerger 2002). Finally, children with extremely low risk profiles, experiencing both individual and structural barriers, will be impervious to these social influences and are expected to refrain from delinquency altogether. ${ }^{1}$

\footnotetext{
${ }^{1}$ In her latest fine-tuning of the taxonomy Moffitt (2006) has argued for an additional fourth group, the low-level chronics. These individual's share many individual and family characteristics with the high-level persistent delinquents, yet show persistent, but not high-level delinquent trajectories. Presumably, they also have off-putting characteristics that exclude them from delinquent peer groups, such as anxieties or phobias.
}

\section{From Parenting Dimensions to Parenting Styles}

The vast majority of studies on the family-delinquency association have treated the family as a potential risk factor for delinquent behavior. Family risk factors include characteristics of parenting as well as other family-related issues such as marital discord, psycho-social problems of parents, and delinquency within the family (Loeber and StouthamerLoeber 1986). However, research adopting this risk factor approach is variable-centered, identifying differences among families on single dimensions, such as harsh parental discipline, supervision, and control, but not considering how these various dimensions coalesce within specific families. Several scholars have argued that adopting a typological approach is more suitable for studying a complex system such as a family (Bergman and Magnusson 1997). This approach combines aspects of variable- and casecentered approaches in which the whole functioning of the system is the unit of analysis by empirically organizing the variety of characteristics and dynamics of families (Henry et al. 2005; Mandara 2003; Mandara and Murray 2002).

An influential typology concerning the parenting context has been developed by Maccoby and Martin (1983). Elaborating on the work of Baumrind (1971), Maccoby and Martin proposed a typology, defining parenting styles according to a two-dimensional framework which consists of: (1) support, such as warmth, acceptance, affection, and responsiveness; and (2) control, which refers to punishment, restrictiveness, supervision, inductive parenting, and conformity demands. They identified four parenting styles: authoritarian (low support, high control), authoritative (high support and control), permissive (high support and low control), and neglecting (low support and control). Parenting styles are configurations of attitudes and behaviors of parents towards their child and create a context or a climate for the parent's behavior. A parenting style is not considered domain specific; that is, it is displayed across many different situations (Darling and Steinberg 1993). This multidimensional approach may consequently more fully cover the facets of child-rearing and may provide a more comprehensive understanding of the influence of patterns of parenting characteristics on the development of delinquency than single parenting characteristics commonly used as risk factors in predicting delinquency.

\section{Prior Research and Current Focus}

Findings from empirical research analyzing whether different delinquency trajectories are associated with different family factors are mixed. Some studies found at least partially different familial etiologies for different trajectories (Chung et al. 2002a, b; Fergusson et al. 2000; 
McDermott and Nagin 2001; Wiesner and Silbereisen 2003; Wiesner and Windle 2004), whereas other studies found no or very few differences (Nagin et al. 1995; White et al. 2001; Wiesner and Capaldi 2003). Although many theories attribute an important role to childhood parenting in the etiology of delinquency, most studies focused on family risk factors other than parenting, such as parental criminality, parental stress and family structure (Fergusson and Horwood 2002; Fergusson et al. 2000; McDermott and Nagin 2001) or examined only one or two single parenting dimensions in relation to delinquency trajectories (Nagin et al. 1995; White et al. 2001; Wiesner and Silbereisen 2003). To our knowledge, one study analyzed the link between family functioning patterns and offending trajectories. Gorman-Smith et al. (2000) found that struggling families (low in discipline, monitoring, structure, cohesion and beliefs) which may be comparable to the neglectful style, were found to be at increased risk for each type of offending, whereas exceptionally functioning families (high levels of positive parenting, adequate discipline, structure, and cohesion) were less likely to be involved in each of the offending patterns. Task-oriented families (high levels of structure, but low levels of warmth and beliefs about the family), which may be relatively similar to the authoritarian parenting style, appeared more likely to be involved in the serious chronic pattern of offending. Thus, although this study covered a relatively limited period of 4 years in middle adolescence, a concurrent link between patterns of family functioning and offending behavior was identified.

The present study builds on research on offending trajectories by analyzing the existence of distinct delinquency trajectories in a longitudinal sample of males who participated in the Pittsburgh Youth Study (PYS; Loeber et al. 1998). It adds to previous studies in at least four ways. First, the PYS covers a period of 14 years with 18 waves. We use data measured at ages 7 up to 19. Many previous studies applying trajectory analysis on self-report data had smaller numbers of assessments covering shorter periods (e.g., Chung et al. 2002a, b; Wiesner and Windle 2004). Second, whereas many previous studies conducted concurrent analyses measuring both risk factors and delinquency during adolescence (e.g., Gorman-Smith et al. 2000), in the present study risk factors were measured in childhood, thus before delinquency trajectory data was collected. Moreover, although most theories explaining delinquent behavior by family characteristics state that parenting and family influences are strongest during childhood (Gottfredson and Hirschi 1990; Moffitt and Caspi 2001), most previous studies concentrated on family factors measured during adolescence. Third, we further extend previous research by focusing on parenting styles instead of family factors in order to gain more insight in the influence of multidimensional styles of how parents interact with their children and whether these are linked to distinctive delinquency patterns across adolescence. Unlike previous studies our focus is on a broad range of parenting characteristics, including supportive and disciplining parenting behaviors and the quality of the relationship between parent and child. In addition, we control for risk factors known to be important, such as socioeconomic status and prior delinquent behavior (e.g., Farrington 2002). Fourth, parenting and all other risk factors were measured across six waves covering middle childhood rather than a snapshot of one point in time.

In sum, general theories of delinquency have argued that family risk factors discriminate between delinquents and non-delinquents. Indeed, there is extensive empirical evidence for family risk factors to explain level differences in delinquency. However, whether distinct delinquency trajectories are linked to different parenting styles is still ambiguous. Therefore, this paper addresses the following research questions: (1) which distinctive delinquency trajectories are empirically identifiable using self-reported and official delinquency from late childhood through late adolescence? (2) What are the delinquency characteristics of the trajectory groups? (3) Do parenting styles, which we consider to be composites of behaviors or relationships in which the parent and child are directly involved, differentiate between the offending trajectory groups, above and beyond prior delinquent behavior and demographic variables?

\section{Materials and Methods}

\section{Sample and Procedure}

The Pittsburgh Youth Study is a panel study that began in 1987 following boys from public schools in the inner city of Pittsburgh. The total sample consisted of three cohorts (grades 1,4 and 7). Based on a screening of antisocial behavior during the first assessment, a risk score for antisocial or problem behavior was created with the most antisocial third of the sample (about 30\%) considering the high risk group and the remaining two-thirds of the sample constituting the low risk group. About 500 boys per cohort, 250 from each risk group, were then randomly selected for further follow-up (for detailed information, see Loeber et al. 1998).

For this study we used data from the youngest cohort. The number of participants at the screening was 849 and at the first follow-up assessment 503 (256 high risk and 247 low risk). The average age was 6.5 at the screening and 6.9 at the first follow-up. The screening sample consisted of $56.4 \%$ African Americans and $57.3 \%$ of the first follow-up sample was African American. Many boys were living with their natural mother (94\%) during the first follow-up but only a small percentage of them lived together with their natural father (38.5\%). Demographic differences of the follow-up sample 
compared to the screening sample (normal population) are not large (see Loeber et al. 1998, p. 33, 36).

After the screening, data have been collected by interviewing several informants: the youth, a parent (primary caretaker) and teacher. Also, official data, such as juvenile court records have been collected. Until 1990, follow-ups took place biannually with subsequent measurements conducted yearly until 2000. The youngest cohort has been followed up a total of 18 times until age 20 . Attrition in the Pittsburgh Youth Study was quite low with $82 \%$ of the youngest cohort participating at the 18th assessment (Loeber et al. 2003).

\section{Measures}

Parenting variables We used the parenting data measured in childhood up to age 9.5 to identify parenting styles. Data on the relationship with primary caretaker, supervision, physical punishment, the quality of the caretaker-child communication, and positive parenting strategies were used. Relationship with primary caretaker measured the parents' emotional closeness to the child and the ability to accurately read and understand the child's feelings and/or needs (13 items reported by the boy; 16 items reported by the parent). Supervision measured to what extent the parent has knowledge about the adolescent's whereabouts and friends (four items). Physical punishment assessed to what degree the parent physically punished the child (one item). Communication measured the degree to which the caretaker and the boy communicate about emotions, disagreements, and problems (eight items). Reinforcement assessed the degree to which the parent expresses positive behaviors towards the boy (seven items reported by the boy; nine items reported by the parent). These measures have been described more extensively in Stouthamer-Loeber and Stallings (2007). Internal consistencies of the parenting scales were satisfactory with alphas ranging from 0.66 for supervision to 0.83 for relationship with primary caretaker, with the mean alpha 0.72 . For each variable the informants were the primary caretaker, usually the mother $(91.1 \%)$ and the boy, except for communication which is only reported by the primary caretaker. ${ }^{2}$ Mean scores of the caretaker and boy were used for analyses.

Demographic variables Variables indicating low economic status and ethnicity (African American) were used as control

\footnotetext{
${ }^{2}$ Comparing the scores of the boy and caretaker measured in the first wave revealed that caretakers generally reported more positively about their parenting behavior than their sons. Scores regarding relationship, supervision and reinforcement were significantly different $(t(498)=$ $-2.6, p<0.01, t(489)=-13.31, p<0.001$, and $t(498)=-12.8, p<0.001$, respectively). Physical punishment shows no significant difference.
}

variables in the multivariate analyses. Low socioeconomic status (SES) was measured using the Hollingshead (1975) index of social status. The scores were computed by multiplying the scale value for occupational prestige by a weight of five and the scale value for educational level by a weight of three. If a family had two parents the highest score was selected.

Delinquency For the self-reported measurement of delinquency over the previous year, the Self-Reported Delinquency Scale (SRD) from Elliott et al. (1985) was used together with the Youth Self Report (Achenbach and Edelbrock 1987) items on stealing and fire setting. The informant of delinquent behaviors was the adolescent. The SRD questionnaire covered 22 delinquent acts ranging from petty theft to serious assault. The self-reported data was collected from age 7 up to age 19. In addition to the self-reported data, data were collected on officially registered convictions (45 different offences). Both self-reported data and official data are known to show biases, but in different ways. While serious offending is often underreported in self-report studies, minor offences are usually underreported in official data (Babinski et al. 2001; Maxfield et al. 2000). We therefore combined selfreported delinquency with official data on delinquency for the ages $10-19$. This is especially important since earlier studies have pointed to the influence of the source of delinquency data on the parenting-delinquency link (e.g., Loeber and Stouthamer-Loeber 1986). The General Delinquency Seriousness Classification (Loeber et al. 1998) was used to classify self-reported and official delinquent behaviors (ages 10-19) as follows: No delinquency (level 0); Minor delinquency at home, including minor vandalism and stealing at home (level 1); Minor delinquency outside home, such as minor vandalism and fire setting with insignificant damage, shoplifting, and avoid paying (level 2); Moderately serious delinquency including pickpocketing, stealing from car, using illegal checks, and carrying weapons (level 3); Serious delinquency including murder, rape, robbery, and selling hard drugs (level 4), and Two or more serious level 4-offences (level 5). This classification places a boy in the category of the most serious delinquent act committed in the last year. The delinquency seriousness classification was based on work of Wolfgang et al. (1985) ${ }^{3}$ Prior delinquency consisted of a summary measure of delinquency seriousness (selfreported) that took place before age 10 and was used as a

\footnotetext{
${ }^{3}$ Conviction records registered criminal acts that were not accounted for in the self-report questionnaire including the possession and selling of various drugs (11 items), liquor law offences, status offences, and traffic offences. Official delinquency seriousness and self-reported delinquency seriousness were significantly linked in seven out of ten waves (Chi-squares ranged from 5.70 at age 11 to 76.57 at age 15, with the mean chi-square 37.0). For a detailed overview of the delinquency seriousness classification of the self-reported and official delinquent acts and please contact the first author.
} 
control variable in the multivariate analyses. For descriptive purposes we also used data on types of delinquency, that is, the proportion of theft, violence, vandalism, fraud $^{4}$, and other delinquent behaviors based on self-reported and official data between ages 10 and 19, total delinquency frequency, that is, the number of delinquent behaviors in the period of ages 10 up to 19, and total number of convictions between ages 10-19.

The variables that were measured during middle childhood (parenting variables, demographic characteristic, and prior delinquency) had ordinal scales and were measured at six waves (ages 7-9.5). These variables were blocked by averaging the scores for each risk factor in order to improve the reliability of the data. For adding them as risk factors in the analyses the blocked constructs for low socioeconomic status and prior delinquency were dichotomized in the values 0 for the neutral part and 1 to indicate a risk effect. Percentiles at approximately 25 and $75 \%$ were used for cut-off scores. This cut-off point was based on previous analyses of the PYS data that resulted in a prevalence of about $25 \%$ serious delinquents in the risk population. All measures mentioned above have been described extensively in earlier publications (e.g., Loeber et al. 1998; Loeber et al. 2007).

\section{Analytic Strategy}

We checked for outliers within a parenting variable on the basis of standardized $z$-values larger than 3.29 or smaller than -3.29 (Tabachnick and Fidell 1989). Outliers were corrected to values that corresponded with 3.29 standard deviations below or above the mean. The self-reported frequency of delinquency which was used for descriptive purposes was corrected for outliers by transforming yearly counts above 365 into 365 .

To identify parenting styles in the PYS data, we applied cluster analyses on the ordinal parenting variables measured up to age 9.5. To derive parenting styles multivariate methods are favored over bivariate approaches (Mandara 2003). Instead of defining parenting styles a priori based on subjective cut-off scores (e.g., Bronte Tinkew et al. 2006), in cluster analysis families are grouped according to their scores on a range of parenting characteristics (Henry et al. 2005). Cluster analysis also allows there to be more important dimensions than the two dimensions (i.e., support and control) on which most bivariate approach studies are based. Following the analytic strategy described in detail in Appendix A we identified a three-cluster solution as the optimal solution.

\footnotetext{
${ }^{4}$ Fraud included using checks illegally, using credit cards without the owner's permission, and cheating someone by selling them worthless goods.
}

To identify types of delinquency trajectories in the PYS data we used a semi-parametric model especially developed to study group based-developmental trajectories (Nagin 2005) using a SAS-based procedure (Jones et al. 2001). Conventional growth-curve models produce a mean estimated growth curve for the population and make the assumption that variation in the growth-curve parameters (level, shape) is normally distributed across individuals. Group-based models circumvent this normality assumption and approximate individual variation in trajectories by a number of discreet groups. The model used here links delinquency seriousness and age by a cubic function permitting parameters to vary freely across a finite number of groups. Consequently, the delinquency trajectory of each group may differ both in level and shape. We estimated models from one to eight groups. ${ }^{5}$ Based on the Bayesian Information Criterion (BIC) a fivegroup model proved to be the optimal solution for our data. The five-group model also performed well on the additional criteria to assess model fit reported by Nagin (2005). In addition to the trajectories themselves, the group-based model produces a probability of membership for each of the distinguished delinquency trajectory groups for each individual in the sample. In describing the different trajectories each boy was assigned to the trajectory group for which his posterior probability of group membership was highest. Indicators of model fit, parameter estimates and mean posterior probabilities are presented in Appendix B.

Subsequently, a multinomial logit model was used to sort out the redundancy among parenting styles and to control for risk factors, such as demographics, and prior delinquency. This model tested whether a parenting style affects the probability of group membership in each of the delinquency trajectory groups relative to the nondelinquency group. In addition, we conducted Wald tests to examine potential differences in risk factors between delinquency trajectories, that is, the trajectories excluding the nondelinquency trajectory.

\section{Results}

\section{Description of the Trajectories}

Five distinct delinquency trajectories were identified (Fig. 1). Based on the overall level of the Delinquency Seriousness Classification (DSC) and the slope of development with age the five trajectories were labeled: (1) nondelinquent trajectory, which constituted $27.2 \%$ of the sample and consisted of boys reporting hardly any delinquent acts, (2) minor

\footnotetext{
${ }^{5}$ Trajectory parameters were estimated by maximum likelihood under the assumption that within trajectory groups delinquency seriousness followed a (zero-inflated) Poisson process. Each model was optimized by testing linear and cubic functions for each trajectory and the non-delinquent and minor delinquent trajectory were set at linear in the final model.
} 
persisting trajectory $(27.6 \%)$, comprised of boys more steadily reporting non-serious delinquency, (3) moderate desisting trajectory $(6.8 \%)$ with boys showing more serious delinquency in their early teens, followed by a steep decline, (4) serious persisting trajectory $(24.2 \%)$ with boys continually reporting serious delinquency throughout the follow-up period, and (5) serious desisting trajectory (14.3\%) made up of boys showing high levels of serious delinquency, peaking in their mid-teens, but showing marked desistance from delinquency from ages 14 to $19 .{ }^{6}$

Additional Wald tests showed the serious persisting trajectory to be different both in level and shape from all other trajectories. Wald tests for the moderate and serious desister trajectories did not reject the hypothesis that these trajectories were similar, as did tests for the non- and minor delinquent trajectories. These groups did however show substantive differences on other offending characteristics reported below, which suggest that these trajectories should not be combined. ${ }^{7}$

The nondelinquent and minor persisting group differed most notably from the other trajectories in that their peak levels of delinquency seriousness never exceeded the DSClevel 1 (Table 1). Estimated seriousness for the moderate desisting trajectory peaked at 1.7 and unlike the minor persisters, their trajectory showed a rapid decline with age. The serious persisting and serious desisting showed the highest levels of delinquency seriousness, with peak-level estimates of 2.4 and 3.0, respectively.

Frequency of delinquency based on self-reported or official data largely corresponded with the overall level of delinquency seriousness: the higher the overall level of delinquency seriousness the higher the average number of delinquent acts committed by boys on each of the five trajectories (Table 1). A noteworthy exception is that both the number of self-reported and officially recorded delinquent acts was much higher in the minor persisting than in the moderate desisting trajectory, whereas their overall delinquency seriousness was relatively similar. Boys on the minor persisting trajectory thus engaged in minor acts of delinquency relatively often, while boys in the moderate desisting trajectory committed much less though more serious delinquency.

Across all groups the majority of the self-reported delinquent acts involved theft (Table 1). The proportion of vandalism was relatively similar as well. Boys on the moderate desisting trajectory however diverged from boys on the other delinquent trajectories by showing markedly less

\footnotetext{
${ }^{6}$ In order to test the robustness of the model we repeated the analyses on a subsample of boys reporting at least some delinquency during the follow-up period (i.e., nondelinquents were excluded). A four-group model was now found to be most optimal $(\mathrm{BIC}=-5,333.3)$ which trajectories matched the four delinquent trajectories in the original model $(\kappa=0.976 ; N=409)$.

${ }^{7}$ Also notice that these tests do not prove these trajectories to be similar: they can only reject the null hypothesis, not prove it.
}

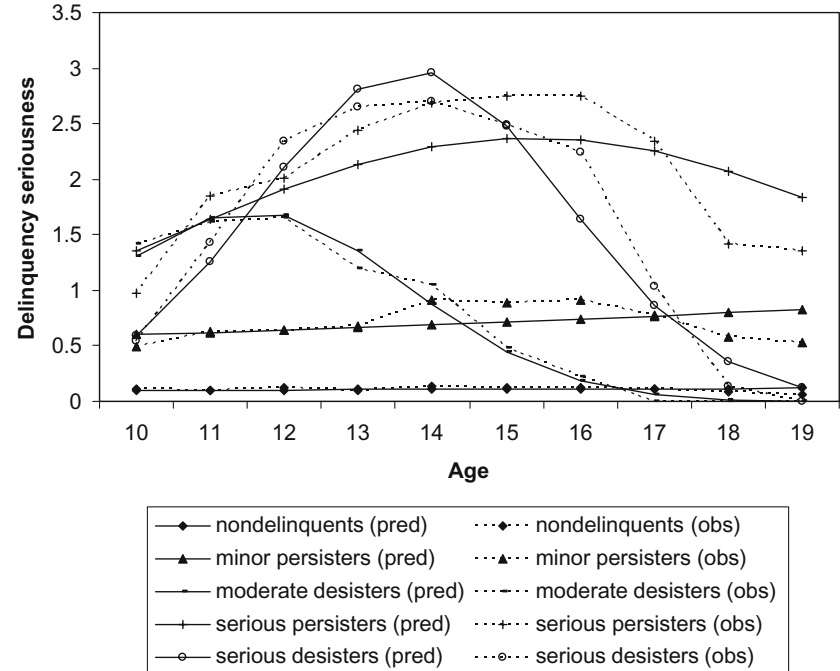

Fig. 1 Predicted (pred) and observed (obs) mean delinquency seriousness for all trajectories

violence (2.4\%), and engaging most often in fraud (28.2\%) such as using checks illegally and selling worthless goods, or other delinquency (18.8\%). Furthermore, serious persisters were characterized by their high involvement in violent offences $(20.6 \%)$, while the serious desisting trajectory showed relatively the most theft $(54.0 \%)$ and the least fraud (11.7\%), compared to the remaining delinquent trajectories.

\section{Parenting Styles as Predictors}

The cluster analysis identified three different parenting styles (see Appendix A for details). Authoritative caretakers were characterized as highly supportive reflected in a relatively good relationship with their child, a high score on positive parenting (i.e., rewarding the child when he has done something good), and high communicative skills. They were also skilled in disciplining their child: they adequately supervised the child, while not using physical punishment as a discipline technique. Authoritarian caretakers (moderately supportive) scored relatively high on discipline characteristics, showing high levels of supervision and physically punishing their youngsters. Moreover, these parents had moderate scores on supportive variables such as relationship, communication, and positive parenting. Neglectful parents had the worst relationship with their children and their discipline techniques were also inadequate. They poorly supervised and physically punished their boys.

In order to assess whether parenting styles were linked to trajectory group membership, dummy indicators of parenting styles were added as risk factors to the trajectory model. ${ }^{8}$ The authoritative category was chosen as a control

\footnotetext{
${ }^{8}$ By estimating the association of these risk factors with trajectory group membership jointly with the trajectories themselves, uncertainty in trajectory membership is taken into account.
} 
Table 1 Delinquency characteristics of the offending trajectories

Figures are means per trajectory group, based on delinquency data measured from ages 10 up to 19. Self-reported delinquency and number of convictions are counts. Delinquency seriousness and crime mix percentages are based on self-reported and official data. The overall association between the seriousness and frequency of delinquency is significant $(r=0.53, p<0.001$, for self-reported and $r=0.59$, $p<0.001$, for official delinquency frequency).

\begin{tabular}{lccccc}
\hline & $\begin{array}{l}\text { Nondelinquents } \\
(n=155)\end{array}$ & $\begin{array}{l}\text { Minor } \\
\text { persisting } \\
(n=124)\end{array}$ & $\begin{array}{l}\text { Moderate } \\
\text { desisting } \\
(n=32)\end{array}$ & $\begin{array}{l}\text { Serious } \\
\text { persisting } \\
(n=111)\end{array}$ & $\begin{array}{l}\text { Serious } \\
\text { desisting } \\
(n=81)\end{array}$ \\
\hline General delinquency & & & & & \\
Delinquency seriousness & 0.1 & 0.7 & 0.8 & 2.1 & 1.6 \\
Peak level & 0.1 & 0.8 & 1.7 & 2.4 & 3.0 \\
Peak age & 19 & 19 & 12 & 15 & 14 \\
Self-reported delinquency & 1.0 & 15.1 & 8.9 & 109.2 & 66.6 \\
Number of convictions & 0.1 & 1.4 & 0.1 & 5.5 & 4.0 \\
Crime mix (percentages) & & & & & 0.0 \\
Nondelinquent & 59.4 & 0.0 & 0.0 & 0.0 & 0.0 \\
Theft & 11.3 & 46.1 & 37.4 & 48.8 & 54.0 \\
Violence & 4.2 & 16.0 & 2.4 & 20.6 & 16.1 \\
Vandalism & 3.2 & 13.1 & 13.3 & 15.5 & 13.1 \\
Fraud & 3.9 & 15.1 & 28.2 & 14.1 & 11.7 \\
Other & 18.1 & 9.7 & 18.8 & 0.9 & 5.0 \\
Total & 100.0 & 100.0 & 100.0 & 100.0 & 100.0 \\
\hline
\end{tabular}

group since prior research clearly indicated that this style is related to positive child outcomes (e.g., Darling and Steinberg 1993; Maccoby and Martin 1983). Demographic variables (ethnicity and socioeconomic status) and an indicator of prior delinquency seriousness (before age 10) were also included as control variables. In all analyses the nondelinquent trajectory was used as a reference group, that is, the risk factor means for all the other trajectories were tested against the nondelinquent trajectory. We tested three multivariate models: (I) a model with only demographic variables, (II) a model with demographic variables and prior delinquency seriousness, and (IIII) the full model including demographic variables, prior delinquency seriousness, and parenting styles (authoritarian and neglectful styles). Results for Model I (Table 2) showed a significantly larger proportion of African Americans on both serious delinquency trajectories (serious persisting and serious desisting). This difference disappeared when parenting styles were added to the model indicating the effects of ethnicity to largely result from differences in parenting style. Somewhat surprisingly, although nondelinquents have the lowest proportion of families with a low socioeconomic status (Table 3), socioeconomic status does not differentiate between trajectories (Table 2).

From models II and III it became clear that prior delinquency seriousness was an important risk factor for later delinquency. However, although prior delinquency differentiated nondelinquents from delinquents, Wald tests showed that this risk factor did not differentiate the remaining four delinquent trajectories very well. Prior delinquency was only significantly different between the serious and minor persisting delinquency trajectories $\left(\chi^{2}(1)=\right.$ 9.09, $p<0.01$ ) in model II. In the full model (model III), no significant differences in prior delinquency were found between the delinquent trajectories (i.e., all trajectories except nondelinquency).

A neglectful parenting style was significantly linked to membership in the moderate desisting trajectory and the serious persisting and desisting trajectories compared to the nondelinquent trajectory. Furthermore, Wald tests revealed significant differences between serious persisting and serious desisting delinquents and minor persisters $\left(\chi^{2}(1)=\right.$ $3.89, p<0.05$ for serious persisting versus minor persisting; $\chi^{2}(1)=5.54, p<0.05$ for serious desisting versus minor persisting), suggesting that a neglectful parenting style primarily distinguished between moderate to serious trajectories and non- to minor trajectories (i.e., moderate desisting, serious persisting, and serious desisting versus nondelinquent and minor persisting). In addition to neglectful parenting being abundant, boys on the serious persisting trajectory also originated significantly more often from authoritarian families compared to the nondelinquents (see Table 2, model III).

\section{Discussion}

Prompted by recent theories distinguishing different developmental pathways and the role attributed by these theories to parenting in the etiology of these pathways, we set out to test whether there was evidence for adolescent boys to follow different trajectories of delinquency seriousness and whether these trajectories were linked to caretakers' parenting styles during childhood. Using person-centered methods and adopting a multidimensional perspective on parenting we identified five delinquency trajectories and three parenting styles. Parenting styles were differentially linked to delinquency with neglectful parenting linked to moderate desisting and serious 
Table 2 Multivariate tests of differences in background, prior delinquency, and parenting style between offending trajectories
Numbers are multinomial logit coefficients with standard errors given in parentheses.

Trajectory 1 is used as a reference group. The $\mathrm{BIC}$ is

$-5,598.3$ for model I, $-5,447.9$

for model II, and $-5,459.9$ for model III.

${ }^{*} p<0.05$

$* * p<0.01$

$* * * p<0.001$

$* * * * p<0.10$

\begin{tabular}{|c|c|c|c|c|c|}
\hline & $\begin{array}{l}\text { Nondelinquents } \\
(27.2 \%)\end{array}$ & $\begin{array}{l}\text { Minor } \\
\text { persisting } \\
(27.6 \%)\end{array}$ & $\begin{array}{l}\text { Moderate } \\
\text { desisting } \\
(6.8 \%)\end{array}$ & $\begin{array}{l}\text { Serious } \\
\text { persisting } \\
(24.2 \%)\end{array}$ & $\begin{array}{l}\text { Serious } \\
\text { desisting } \\
(14.3 \%)\end{array}$ \\
\hline \multicolumn{6}{|l|}{ Model I } \\
\hline \multicolumn{6}{|l|}{ Demographics } \\
\hline African Americans & - & $0.60(0.39)$ & $-0.04(0.50)$ & $0.86(0.30)^{* *}$ & $1.04(0.41)^{*}$ \\
\hline Low SES & - & $0.50(0.47)$ & $0.19(0.69)$ & $0.50(0.38)$ & $0.80(0.45)^{* * * *}$ \\
\hline \multicolumn{6}{|l|}{ Model II } \\
\hline \multicolumn{6}{|l|}{ Demographics } \\
\hline African Americans & - & $0.66(0.39)^{* * * *}$ & $0.10(0.55)$ & $0.76(0.38)^{*}$ & $1.05(0.44)^{*}$ \\
\hline Low SES & - & $0.96(0.49)^{*}$ & $0.38(0.86)$ & $0.89(0.49)^{* * * *}$ & $1.07(1.52)^{*}$ \\
\hline \multicolumn{6}{|l|}{ Delinquency } \\
\hline Prior delinquency & - & $0.98(0.20)^{* * *}$ & $1.25(0.30)^{* * *}$ & $1.58(0.22)^{* * *}$ & $1.21(0.23)^{* * *}$ \\
\hline \multicolumn{6}{|l|}{ Model III } \\
\hline \multicolumn{6}{|l|}{ Demographics } \\
\hline African Americans & - & $0.68(0.37)^{* * * *}$ & $-0.26(0.60)$ & $0.44(0.43)$ & $0.98(0.52)^{* * * *}$ \\
\hline Low SES & - & $0.88(0.47)^{* * * *}$ & $0.33(0.81)$ & $0.50(0.50)$ & $0.58(0.59)$ \\
\hline \multicolumn{6}{|l|}{ Delinquency } \\
\hline Prior delinquency & - & $0.87(0.20)^{* * *}$ & $1.20(0.30)^{* * *}$ & $0.25(0.25)^{* * *}$ & $1.03(0.25)^{* * *}$ \\
\hline \multicolumn{6}{|l|}{ Parenting Style } \\
\hline Authoritarian style & - & $0.59(0.40)$ & $1.70(1.02)^{* * * *}$ & $0.48(0.48)^{*}$ & $0.28(0.59)$ \\
\hline Neglectful Style & - & $0.55(0.72)$ & $2.44(1.20)^{*}$ & $0.71(0.71)^{*}$ & $1.96(0.69)^{* *}$ \\
\hline
\end{tabular}

persisting and desisting trajectories and authoritarian parenting linked to serious persistent delinquency.

While the trajectories identified in this study resemble those postulated by developmental theories to some extent, there are also marked differences. Within the limits of our data range we identified a minor and serious 'persistent' group of boys continuously showing delinquent behavior resembling Moffitt's (2006) low chronic and life-course persistent trajectories both in level and age-pattern. Our serious desisting trajectory most closely resembled the adolescent-limited pathway: starting with minor delinquency in late childhood and rapidly escalating to relatively serious delinquency in early adolescence. This escalation process of delinquency seriousness has been described in the literature (e.g., Farrington 1997; Hawkins et al. 1998; Lipsey and Derzon 1998; Loeber et al. 2007). Yet, these boys constituted only $14 \%$ of the entire sample, while adolescence-limited delinquents were predicted to be common by the typology. Furthermore, over one in four of the boys reported no or hardly any delinquency during the 10 year-follow-up. Given the high risk nature of the Pittsburgh sample, this is at odds with the Moffitt typology which predicted abstainers to be a very rare phenomenon. Finally, we identified a moderate desisting trajectory with boys showing a marked decrease in delinquency seriousness from a peak at age 12 to virtually zero at age 19 .

Given that most studies focus on delinquency frequency data (e.g., McDermott and Nagin 2001; Nagin et al. 1995; White et al. 2001; Wiesner and Silbereisen 2003), discrepancies between our and prior findings and theoretical predictions underscore the importance of considering other indicators of delinquency such as seriousness and offence
Table 3 Means of background, prior delinquency, and parenting style for each offending trajectory based on the multinomal logit model (model III)

Prior delinquency is the delinquency seriousness classification during childhood (ages 7 up to 9.5) based on self-reports. The remaining means are proportions as the variables are dichotomous.

\begin{tabular}{|c|c|c|c|c|c|}
\hline & $\begin{array}{l}\text { Nondelinquents } \\
(n=129)\end{array}$ & $\begin{array}{l}\text { Minor } \\
\text { persisting } \\
(n=161)\end{array}$ & $\begin{array}{l}\text { Moderate } \\
\text { desisting } \\
(n=33)\end{array}$ & $\begin{array}{l}\text { Serious } \\
\text { persisting } \\
(n=101)\end{array}$ & $\begin{array}{l}\text { Serious } \\
\text { desisting } \\
(n=59)\end{array}$ \\
\hline \multicolumn{6}{|c|}{ Demographic variables } \\
\hline African Americans & 0.39 & 0.66 & 0.39 & 0.63 & 0.73 \\
\hline Low SES & 0.12 & 0.29 & 0.15 & 0.23 & 0.24 \\
\hline \multicolumn{6}{|l|}{ Delinquency } \\
\hline Prior delinquency & 0.60 & 1.56 & 2.06 & 2.31 & 1.90 \\
\hline \multicolumn{6}{|l|}{ Parenting styles } \\
\hline Authoritarian style & 0.32 & 0.50 & 0.58 & 0.51 & 0.25 \\
\hline Neglectful style & 0.05 & 0.14 & 0.33 & 0.31 & 0.47 \\
\hline
\end{tabular}


type. To our knowledge, a group starting young with relatively serious delinquency levels but desisting early has not been identified previously. Notably, despite the fact that delinquency in these boys was relatively serious at a young age, the frequency of delinquency was rather low. Moreover, this group of boys reported very low levels of aggressive acts. Clearly, levels of delinquency seriousness are not necessarily related to the level of delinquency frequency.

This study aimed to analyze whether parenting styles were differentially associated with delinquency trajectories. A neglectful punishing style distinguished the moderate to serious trajectories from the nondelinquent and minor trajectories above and beyond childhood delinquency and demographic characteristics such as socioeconomic status and ethnicity. Even moderate desisters originated more often from neglectful families than nondelinquents. Notably, these youngsters had conviction rates that are comparable to nondelinquents, yet they committed relatively serious offences at younger ages. Our findings are in accordance with results from previous studies resulting in a link between a neglectful style and delinquency (Maccoby and Martin 1983; Steinberg et al. 1994). Furthermore, the neglectful style in our sample is similar to the concept of poor parenting described by Moffitt and Caspi (2001).

General theories state that high levels of poor parenting lead to high levels of delinquency, while typological theories argue that different types of delinquent trajectories stem from different etiological backgrounds. In the present study we found significant differences in parenting styles between delinquency trajectories, that is, differences between more serious and minor delinquency trajectories, yet parenting styles did not distinguish among the more serious trajectories. This finding is similar to that of White et al. (2001) who found the same family risk factors for adolescence-limited and life-course persistent delinquents. An explanation could be that parenting styles may not predict delinquency patterns later than early adolescence. While the boys following a moderate desisting and serious persisting pathways are similar during late childhood (i.e., at ages 10-11), with both displaying relatively high levels of delinquency seriousness at young age, the former experienced marked desistance as of age 11, while the latter did not. However, neither parenting styles nor prior delinquency (in middle childhood) could differentially predict membership for these groups. This suggests that neglectful parenting and delinquency during childhood can only partially predict development in delinquency over longer periods of time (i.e., after age 13). This is in accordance with previous research focusing on long-term association between parenting and delinquency (e.g., Farrington and Hawkins 1991; Hoeve et al. 2007; Sampson and Laub 1993).
Interestingly, many of the theories that attribute an important role to childhood parenting in the etiology of delinquency conceive this role primarily as facilitating the development of some stable tendency towards delinquency (e.g., Gottfredson and Hirschi 1990; Moffitt 1993). Behavioral patterns originating in the family quickly become ingrained and increasingly hard to alter as children age. However, according to Sampson and Laub (2005) and others, changes in life circumstances are able to effectuate change in an individual's delinquent trajectory, notwithstanding the individual's rearing environment. Moreover, delinquency during adolescence is governed not only by bonds to the family, but also by bonds to peers, school and later work and romantic partners. Changes in any of these bonds continue to affect delinquent development. Since parenting styles and parenting dimensions have been found to be relatively stable over time (e.g., Holden and Miller 1999; Loeber et al. 2000; Steinberg et al. 1994), for the desisting groups bonds to school and peers may have become more salient in explaining delinquency during midand late adolescence than bonds to parents (Sampson and Laub 2005). ${ }^{9}$ The transition from primary to middle school and its changing opportunities for new friends and extracurricular activities may have set a group of boys off on a desisting pathway. Wiesner and Capaldi (2003) found that among adolescents with similar parenting experiences during childhood, low level offenders during adolescence were less involved with deviant peers than those youth who became high level offenders. Other life circumstances could have changed the delinquent pathway of some boys as well. For example, desisting youngsters may have participated in intervention programs.

Among the strengths of this study are the use of multiple informants, analyzing prospective relations between parenting and delinquency trajectories, examining a varied set of parenting characteristics to identify parenting styles, and besides assessing a broad range of delinquent acts combining self-reported and official delinquency data. However, several limitations should also be noted. First, a convicted boy may receive a custodial sentence which may influence the total time that a boy is actually at risk for committing delinquent acts. Prior research has shown that not controlling for exposure time may yield suppressed estimates of

\footnotetext{
${ }^{9}$ Although we focused on childhood predictors of delinquency trajectories, we conducted post-hoc analyses on whether bonds to parents improved when boys desisted from moderate levels of delinquency, using the data on the quality of the caretaker-child relationship. The quality of the parent-child relationship in early adolescence (ages 13-16) improved slightly compared to levels in late childhood (ages 10-12), however, this bond improved for all boys in the sample. Thus, a change in bonds to parents is unlikely to explain the decreasing level of delinquency in the moderate desisting trajectory.
} 
actual delinquency frequency (McCaffrey et al. 2007) and may account for much of the decline in delinquent trajectories past peak age (Piquero et al. 2001). Mathematical solutions offered to deal with this 'false' desistance, typically require data on incarceration. Unfortunately, official data on custodial sentences were not available for the PYS-sample. To gain some insight in the sensitivity of our findings to the possible bias of false desistance, we tested the five-group model on the subset of boys who were never convicted, and thus did not experience reduced risk of offending due to incarceration between ages 10 and 19 . This resulted in trajectories with similar shapes and a classification of boys into similar groups $(\kappa=0.93 ; N=$ 324). ${ }^{10}$ A second limitation is the fact that the youngest sample has been followed up only until late adolescence and as a consequence we were not able to distinguish true life-course persistent offenders into adulthood. However, the PYS is an ongoing study and a follow-up is currently underway. A third limitation is that the sample consisted only of boys. Both delinquency trajectories as well as their associations to parenting styles could be different for girls. Future studies should focus on girls' delinquency trajectories and whether these relate to parenting.

Given that we found strong links between parenting styles and delinquency trajectories, we recommend that researchers include parenting styles or at least both elements of support and control measurements in their investigation. The typological approach offers an analytic strategy in which combinations of these parenting dimensions may more closely reflect the interactional nature of parenting dynamics and may have higher predictive value (Mandara 2003). Whereas many theories consider a particular parenting characteristic to be responsible for delinquent development (e.g., Hirschi 1969; Patterson 1982; Sampson and Laub 1993), our study shows that a neglectful parenting pattern consisting of a combination of low levels of warmth and support, inadequate discipline techniques, and harsh punishment predicts several serious delinquency trajectories.

These results have implications for family-oriented prevention strategies in that they provide information on which combinations of parenting dimensions are particularly relevant. Preventive actions should focus on neglectful families characterized by harsh punishment, inadequate discipline, and low levels of supportive parenting in their

\footnotetext{
${ }^{10}$ We also estimated models were we added time varying variables indicating periods during which a boy was liable to be at reduced risk of engaging in delinquent activities due to incarceration, based on the both occurrence and seriousness of convictions within each boy's delinquency trajectory. Both the trajectories estimated by these augmented models and the boys classification to these trajectories were comparable to the original model's results.
}

effort to reduce the risk of youngsters from these families setting off to a future of serious delinquency.

Acknowledgements This work was supported by grants from the Office of Juvenile Justice and Delinquency Prevention, Office of Justice Process, US Department of Justice to the principle investigators of the Pittsburgh Youth Study, Rolf Loeber and Magda Stouthamer-Loeber (OJJDP Grant number OJJDP 2005-JK-FX-0001), and a travel fund from the Radboud University Nijmegen and The Netherlands Organization for Scientific Research (NWO; R 57-232). We are greatly indebted to Wilma Smeenk and Magda StouthamerLoeber for their help and advice at the start of the project and to Rebecca Stallings for her valuable assistance on preparing the data for the analyses.

\section{Appendix A}

We randomly choose about 250 subjects from the sample and conducted a hierarchical cluster analysis (HCA), which is not suitable for samples with over 250 subjects (Everitt et al. 2001), applying the Standardized Euclidian Distance method as a distance measure and using Ward's algorithm to decide how cases are combined at each step (Henry et al. 2005, p. 123; Mandara 2003, p. 137). Variables were standardized as the parenting variables were measured on different scales. By applying visual methods (e.g., inspecting the dendrogram, agglomeration scheme, and Euclidian distances plot), we concluded that three, four, and five clusters could be optimal solutions. Confirmatory analysis, that is, conducting $k$-means on the same subsample and comparing the cluster solutions of three to five clusters to those from the hierarchical cluster analysis resulted in moderate to substantial kappa's $(\kappa=0.78$ for three clusters, $\kappa=0.75$ for four clusters, and $\kappa=0.76$ for five clusters, $N=$ 254). We then divided the overall sample in two subsamples, conducting a $k$-means analysis on both subsamples and calculating the agreement between the two solutions. We repeated this procedure ten times for three, four and five cluster solutions. This cross-validation procedure (Mandara 2003) resulted in moderate agreements ( $\kappa=0.74$, range: $0.44-0.95$ for three clusters, $\kappa=0.73$, range: $0.55-0.86$ for four clusters, and $\kappa=0.68$, range: $0.47-0.83$ for five clusters). The cluster solution with the largest mean kappa gives an indication of the optimal number of clusters (Mandara and Murray 2002). Based on these analyses we choose the three cluster-model as the optimal model. For interpretation reasons we examined the parenting styles by computing a MANOVA on the parenting variables with the clusters serving as the factor (Table 4). The MANOVA revealed that the cluster variables significantly differed between the parenting clusters, Pillai's Trace, $F(10,988)=83.8, p<0.001, \eta^{2}=0.46$. The three groups were labeled on the basis of the most salient parenting characteristics. 
Table 4 Numbers of cases in maternal parenting style groups, and mean scores and analyses (ANOVAs) on parenting variables

\begin{tabular}{|c|c|c|c|c|c|}
\hline & Authoritative & Authoritarian (moderately supportive) & Neglectful (punishing) & $F(2,497)$ & $\eta^{2}$ \\
\hline Frequency & 184 & 218 & 100 & & \\
\hline Percent & 36.7 & 43.4 & 19.9 & & \\
\hline Relationship & $56.8_{\mathrm{a}}$ & $51.8_{\mathrm{b}}$ & $44.0_{\mathrm{c}}$ & $336.64 *$ & 0.58 \\
\hline Physical punishment & $2.8_{\mathrm{a}}$ & $3.5_{\mathrm{b}}$ & $3.5_{\mathrm{b}}$ & $97.23 *$ & 0.28 \\
\hline Supervision & $15.5_{\mathrm{a}}$ & $14.1_{\mathrm{b}}$ & $12.3_{\mathrm{c}}$ & $147.39^{*}$ & 0.37 \\
\hline Communication & $53.3_{\mathrm{a}}$ & $39.9_{\mathrm{b}}$ & $24.0_{\mathrm{c}}$ & $337.96^{*}$ & 0.58 \\
\hline Positive parenting & $25.3_{\mathrm{a}}$ & $23.6_{\mathrm{b}}$ & $20.7_{\mathrm{c}}$ & $125.05^{*}$ & 0.33 \\
\hline
\end{tabular}

Different subscripts in a row indicate significantly different means at $p<0.05$ using post hoc tests with the Games-Howell procedure. Since the assumption of homogeneity of covariances was violated, we equalized the groups by selecting at random cases from groups. This resulted in relatively equal groups (largest group size/smallest group size <1.5; Stevens 1996). Again, we computed a MANOVA which resulted in comparable findings as the original MANOVA test.

$* p<0.001$

\section{Appendix B}

Table 5 Bayesian information criterion (BIC) and BIC Log Bayes factor approximation for two-group to eight-group models

\begin{tabular}{lcc}
\hline No. of groups & BIC & $2 \log _{\mathrm{e}}\left(\mathrm{B}_{10}\right)^{1}$ \\
\hline 2 & $-5,636.3$ & \\
3 & $-5,628.9$ & 14.91 \\
4 & $-5,591.2$ & 75.23 \\
5 & $-5,585.0$ & 12.48 \\
6 & $-5,591.9$ & -13.74 \\
7 & $-5,606.8$ & -29.76 \\
8 & $-5,621.0$ & -28.45 \\
\hline
\end{tabular}

${ }^{1} 2 \log _{\mathrm{e}}\left(\mathrm{B}_{10}\right)>10$ indicates there is very strong evidence that the more complex model is favored above the simpler model (Jones et al. 2001)

Table 6 Numerical values of parameter estimates for trajectory models

\begin{tabular}{|c|c|c|c|c|c|c|c|c|c|c|}
\hline & \multicolumn{2}{|c|}{ Non-delinquents } & \multicolumn{2}{|c|}{ Minor persisters } & \multicolumn{2}{|c|}{ Moderate desisters } & \multicolumn{2}{|c|}{ Serious persisters } & \multicolumn{2}{|c|}{ Serious desisters } \\
\hline & Estimate & SE & Estimate & SE & Estimate & SE & Estimate & SE & Estimate & SE \\
\hline Intercept & & 0.57 & 0.33 & 0.24 & $-14.28 * * *$ & 4.01 & $-3.40 * * *$ & 0.93 & $-20.68 * * *$ & 2.45 \\
\hline Age/10 & 0.20 & 0.39 & $0.35^{*}$ & 0.16 & $26.03 * * *$ & 6.26 & $5.96 * * *$ & 1.30 & $31.96^{* * *}$ & 3.50 \\
\hline$($ Age/10)2 & - & - & - & - & $-11.26^{* * *}$ & 2.40 & $-1.94 * * *$ & 0.45 & $-11.64 * * *$ & 1.25 \\
\hline Alpha & $2.91 * * *$ & 0.36 & $0.84 * * *$ & 0.22 & $-1.43 * *$ & 0.53 & $-1.02 * * *$ & 0.14 & $-1.78 * * *$ & 0.36 \\
\hline
\end{tabular}

${ }^{*} p<.05, * * p<.01, * * * p<.001$

Table 7 Mean assignment probability for the five-group model

${ }^{\text {a }} \mathrm{OCC}_{\mathrm{j}}>5$ indicates high assignment accuracy (Nagin 2005)

\begin{tabular}{llllllr}
\hline & Nondelinquents $(n=155)$ & $\begin{array}{l}\text { Minor } \\
\text { persisting } \\
(n=124)\end{array}$ & $\begin{array}{l}\text { Moderate } \\
\text { desisting } \\
(n=32)\end{array}$ & $\begin{array}{l}\text { Serious } \\
\text { persisting } \\
(n=111)\end{array}$ & $\begin{array}{l}\text { Serious } \\
\text { desisting } \\
(n=81)\end{array}$ & OCC $^{\text {a }}$ \\
\hline Nondelinquent & 0.82 & 0.00 & 0.00 & 0.08 & 0.00 & 12.00 \\
Minor persisting & 0.00 & 0.70 & 0.05 & 0.04 & 0.07 & 6.24 \\
Moderate desisting & 0.01 & 0.03 & 0.75 & 0.05 & 0.00 & 42.11 \\
Serious persisting & 0.18 & 0.07 & 0.17 & 0.75 & 0.06 & 9.43 \\
Serious desisting & 0.00 & 0.19 & 0.02 & 0.07 & 0.87 & 39.64 \\
\hline
\end{tabular}




\section{References}

Achenbach, T. M., \& Edelbrock, C. S. (1987). Manual for the Youth Self-Report and profile. Burlington, VT: Department of Psychiatry, University of Vermont.

Babinski, L. M., Hartsough, C. S., \& Lambert, N. M. (2001). A comparison of self-report of criminal involvement and official arrest records. Aggressive Behavior, 27(1), 44-54.

Baumrind, D. (1971). Current patterns of parental authority. Developmental Psychology, 4(1), 1-103.

Bergman, L. R., \& Magnusson, D. (1997). A person-oriented approach in research on developmental psychopathology. Development and Psychopathology, 9(2), 291-319.

Bronte Tinkew, J., Moore, K. A., \& Carrano, J. (2006). The fatherchild relationship, parenting styles, and adolescent risk behaviors in intact families. Journal of Family Issues, 27(6), 850-881.

Chung, I. J., Hawkins, J. D., Gilchrist, L. D., Hill, K. G., \& Nagin, D. S. (2002a). Identifying and predicting offending trajectories among poor children. Social Service Review, 76(4), 663-685.

Chung, I. J., Hill, K. G., Hawkins, J. D., Gilchrist, L. D., \& Nagin, D. S. (2002b). Childhood predictors of offense trajectories. Journal of Research in Crime and Delinquency, 39(1), 60-90.

Darling, N., \& Steinberg, L. (1993). Parenting style as context: An integrative model. Psychological Bulletin, 113(3), 487-496.

Dishion, T. J., \& Patterson, G. R. (2006). The development and ecology of antisocial behavior in children and adolescents. In D. Cicchetti, \& D. J. Cohen (Eds.), Developmental psychopathology, Vol 3: Risk, disorder, and adaptation (pp. 503-541). Hoboken, NJ: Wiley.

Elliott, D. S., Huizinga, D., \& Ageton, S. S. (1985). Explaining delinquency and drug use. Beverly Hills, CA: Sage.

Everitt, B. S., Landau, S., \& Leese, M. (2001). Cluster analysis. London: Arnold.

Farrington, D. P. (1997). Early Prediction of violent and nonviolent youthfull offending. European Journal on Criminal Policy and Research, 5, 51-66.

Farrington, D. P. (2002). Multiple risk factors for multiple problem violent boys. In R. R. Corrado, R. Roesch, S. D. Hart, \& J. K. Gierowski (Eds.), Multi problem violent youth: A foundation for comparative research on needs, interventions and outcomes, Vol. 324 (pp. 23-34). Amsterdam: IOS

Farrington, D. P., \& Hawkins, J. D. (1991). Predicting participation, early onset and later persistence in officially recorded offending. Criminal Behaviour and Mental Health, 1(1), 1-33.

Fergusson, D. M., \& Horwood, L. J. (2002). Male and female offending trajectories. Development and Psychopathology, 14(1), 159-177.

Fergusson, D. M., Horwood, L. J., \& Nagin, D. S. (2000). Offending trajectories in a New Zealand birth cohort. Criminology, 38(2), 525-551.

Gorman-Smith, D., Tolan, P. H., \& Henry, D. B. (2000). A developmental-ecological model of the relation of family functioning to patterns of delinquency. Journal of Quantitative Criminology, 16(2), 169-198.

Gottfredson, M. R., \& Hirschi, T. (1990). A general theory of crime. Palo Alto: Stanfort University Press.

Hawkins, J. D., Herrenkohl, T., Farrington, D. P., Brewer, D., Catalano, R. F., \& Harachi, T. W. (1998). A review of predictors of youth violence. In R. Loeber \& D. P. Farrington (Eds.), Serious and violent juvenile offenders: Risk factors and successful interventions (pp. 106-146). Thousand Oaks, CA: Sage.

Henry, D. B., Tolan, P. H., \& Gorman-Smith, D. (2005). Cluster analysis in family psychology research. Journal of Family Psychology, 19(1), 121-132.

Hirschi, T. (1969). Causes of delinquency. Berkeley: University of California Press.
Hoeve, M., Smeenk, W. H., Loeber, R., Stouthamer Loeber, M., Van der Laan, P. H., Gerris, J. R. M., et al. (2007). Long term effects of parenting and family characteristics on delinquency of male young adults. European Journal of Criminology, 4(2), 116-194.

Holden, G. W., \& Miller, P. C. (1999). Enduring and different: A meta-analysis of the similarity in parents' child rearing. Psychological Bulletin, 125(2), 223-254.

Hollingshead, A. B. (1975). Four factor index of social status. Unpublished manuscript, New Haven, CT.

Jones, B. L., Nagin, D. S., \& Roeder, K. (2001). A SAS procedure based on mixture models for estimating developmental trajectories. Sociological Methods and Research, 29(3), 374-393.

Lahey, B. B., \& Waldman, I. D. (2003). A developmental propensity model of the origins of conduct problems during childhood and adolescence. In B. B. Lahey, T. E. Moffit \& A. Caspi (Eds.), Causes of conduct disorder and juvenile delinquency (pp. 76117). New York: Guilford.

Lipsey, M. W., \& Derzon, J. H. (1998). Predictors of violent of serious delinquency in adolescence and early adulthood. In R. Loeber \& D. P. Farrington (Eds.), Serious and violent juvenile offenders: Risk factors and successful interventions (pp. 86-105). Thousand Oaks, CA: Sage.

Loeber, R., \& Stouthamer-Loeber, M. (1986). Family factors as correlates and predictors of juvenile conduct problems and delinquency. In M. H. Tonry \& N. Morris (Eds.), Crime and justice: An annual review of research, Vol. 7 (pp. 29-149). Chicago: University of Chicago Press.

Loeber, R., Farrington, D. P., Stouthamer-Loeber, M., \& Van Kammen, W. B. (1998). Antisocial behavior and mental health problems. Mahwah, NJ: Lawrence Erlbaum.

Loeber, R., Drinkwater, M., Yin, Y., Anderson, S. J., Schmidt, L. C., \& Crawford, A. (2000). Stability of family interaction from ages 6 to 18. Journal of Abnormal Child Psychology, 28(4), 353-369.

Loeber, R., Farrington, D. P., Stouthamer-Loeber, M., \& White, H. R. (2007). Violence and serious theft: Development and prediction from childhood to adulthood. Mahwah, NJ: Lawrence Erlbaum (in press).

Loeber, R., Farrington, D. P., Stouthamer-Loeber, M., Moffitt, T. E., Caspi, A., Raskin White, H., et al. (2003). The development of male offending: Key findings from fourteen years of the Pittsburgh Youth Study. In T. Thornberry \& M. Krohn (Eds.), Taking stock of delinquency: An overview of findings from contemporary longitudinal studies. New York: Kluwer.

Maccoby, E. E., \& Martin, J. A. (1983). Socialization in the context of the family: Parent-child interaction. In P. H. Mussen (Ed.), Handbook of child psychology: Socialization, personality and social development, Vol. IV (pp. 1-101). New York: Wiley.

Mandara, J. (2003). The typological approach in child and family psychology: A review of theory, methods, and research. Clinical Child and Family Psychology Review, 6(2), 129-146.

Mandara, J., \& Murray, C. B. (2002). Development of an empirical typology of African American family functioning. Journal of Family Psychology, 16(3), 318-337.

Maxfield, M. G., Weiler, B. L., \& Widom, C. S. (2000). Comparing self-reports and official records of arrests. Journal of Quantitative Criminology, 16(1), 87-110.

McCaffrey, D. F., Morrell, A. R., Ridgeway, G., \& Griffin, B. A. (2007). Interpreting treatment effects when cases are institutionalized after treatment. Drug and Alcohol Dependence, 89, 126-138.

McDermott, S., \& Nagin, D. S. (2001). Same or different? Comparing offender groups and covariates over time. Sociological Methods and Research, 29(3), 282-318.

Moffitt, T. E. (1993). Adolescence-limited and life-course-persistent antisocial behavior: A developmental taxonomy. Psychological Review, 100(4), 674-701.

Moffitt, T. E. (2006). A review of research on the taxonomy of lifecourse persistent versus adolescence-limited antisocial behavior. 
In F. T. Cullen, J. P. Wright \& K. R. Blevins (Eds.), Taking stock: The of criminological theory, Vol. 15 (pp. 277-311). New Brunswick: Transaction.

Moffitt, T. E., \& Caspi, A. (2001). Childhood predictors differentiate life-course-persistent and adolescence-limited antisocial pathways among males and females. Development and Psychopathology, 13(2), 355-375.

Nagin, D. S. (2005). Group-Based Modeling of Development over the Life Course. Cambridge, MA: Harvard University Press.

Nagin, D. S., Farrington, D. P., \& Moffit, T. E. (1995). Life-course trajectories of different types of offenders. Criminology, 33(1), 111-139.

Patterson, G. R. (1982). Coercive family process. Eugene, OR: Castalia.

Patterson, G. R., \& Yoerger, K. (2002). A developmental model for early- and late-onset delinquency. In J. B. Reid, G. R. Patterson \& J. Snyder (Eds.), Antisocial behavior in children and adolescents: A developmental analysis and model for intervention (pp. 147-172). Washington, DC: American Psychological Association.

Piquero, A. R., Blumstein, A., Brame, R., Haapanen, R., Mulvey, E. P., \& Nagin, D. S. (2001). Assessing the impact of exposure time and incapacitation on longitudinal trajectories of criminal offending. Journal of Adolescent Research, 16(1), 54-74.

Sampson, R. J., \& Laub, J. H. (1993). Crime in the making: Pathways and turning points through life. Cambridge, MA: Harvard University Press.

Sampson, R. J., \& Laub, J. H. (2005). A general age-graded theory of crime: Lessons learned and the future of life-course criminology. In D. P. Farrington (Ed.), Integrated developmental and life course theories of offending (Vol. 14). Piscataway, NJ: Transaction.
Steinberg, L., Lamborn, S. D., Darling, N., Mounts, N. S., \& Dornbusch, S. M. (1994). Over-time changes in adjustment and competence among adolescents from authoritative, authoritarian, indulgent, and neglectful families. Child Development, 65(3), 754-770.

Stevens, J. (1996). Applied multivariate statistics for the social sciences. Mahwah, NJ: Lawrence Erlbaum.

Stouthamer-Loeber, M., \& Stallings, R. (2007). Measurement Instruments and Constructs. In R. Loeber, D. P. Farrington, M. Stouthamer-Loeber \& H. R. White (Eds.), Violence and serious theft: Development and prediction from childhood to adulthood. Mahwah, NJ: Lawrence Erlbaum (in press).

Tabachnick, B. G., \& Fidell, L. S. (1989). Using multivariate statistics. New York: HarperCollins.

White, H. R., Bates, M. E., \& Buyske, S. (2001). Adolescence-limited versus persistent delinquency: Extending Moffitt's hypothesis into adulthood. Journal of Abnormal Psychology, 110(4), 600-609.

Wiesner, M., \& Capaldi, D. M. (2003). Relations of childhood and adolescent factors to offending trajectories of young men. Journal of Research in Crime and Delinquency, 40(3), 231-262.

Wiesner, M., \& Silbereisen, R. K. (2003). Trajectories of delinquent behaviour in adolescence and their covariates: Relations with initial and time-averaged factors. Journal of Adolescence, 26, 753-771.

Wiesner, M., \& Windle, M. (2004). Assessing covariates of adolescent delinquency trajectories: A latent growth mixture modeling approach. Journal of Youth and Adolescence, 33(5), 431-442.

Wolfgang, M. E., Figlio, R. M., Tracy, P. E., \& Singer, S. I. (1985). The national survey of crime severity. Washington, DC: US Government Printing Office. 